\title{
Richter's Transformation as leptomeningeal infiltration in a Chronic Lymphocytic Leukemia patient receiving Venetoclax. Could blood-brain barrier be a disease "sanctuary" during Venetoclax treatment?
}

Maria Dimou ${ }^{1}$, Aikaterini Bitsani ${ }^{1}$, Maria Roumelioti ${ }^{1}$, Aglaia Dimitrakopoulou ${ }^{1}$, Theodoros Iliakis ${ }^{1}$, Vasileios Pardalis ${ }^{1}$, Ioannis Grafakos ${ }^{1}$, Sotiria Kalyva ${ }^{1}$, Athanasios Markopoulos $^{1}$, Marie-Christine Kyrtsonis ${ }^{1}$, and Panayiotis Panayiotidis ${ }^{1}$

${ }^{1}$ Laiko General Hospital

January 26, 2021

\begin{abstract}
We present a unique Richter's transformation case in CNS with identical to CLL clonal origin in a patient treated with Venetoclax. With our case we make implications on whether Venetoclax penetrates the blood-brain barrier and we address the debating issue of the appropriate Venetoclax dose in case of drug-drug interactions.
\end{abstract}

\section{Hosted file}

TEXT.pdf available at https://authorea.com/users/389865/articles/505805-richter-stransformation-as-leptomeningeal-infiltration-in-a-chronic-lymphocytic-leukemia-patientreceiving-venetoclax-could-blood-brain-barrier-be-a-disease-sanctuary-during-venetoclaxtreatment 


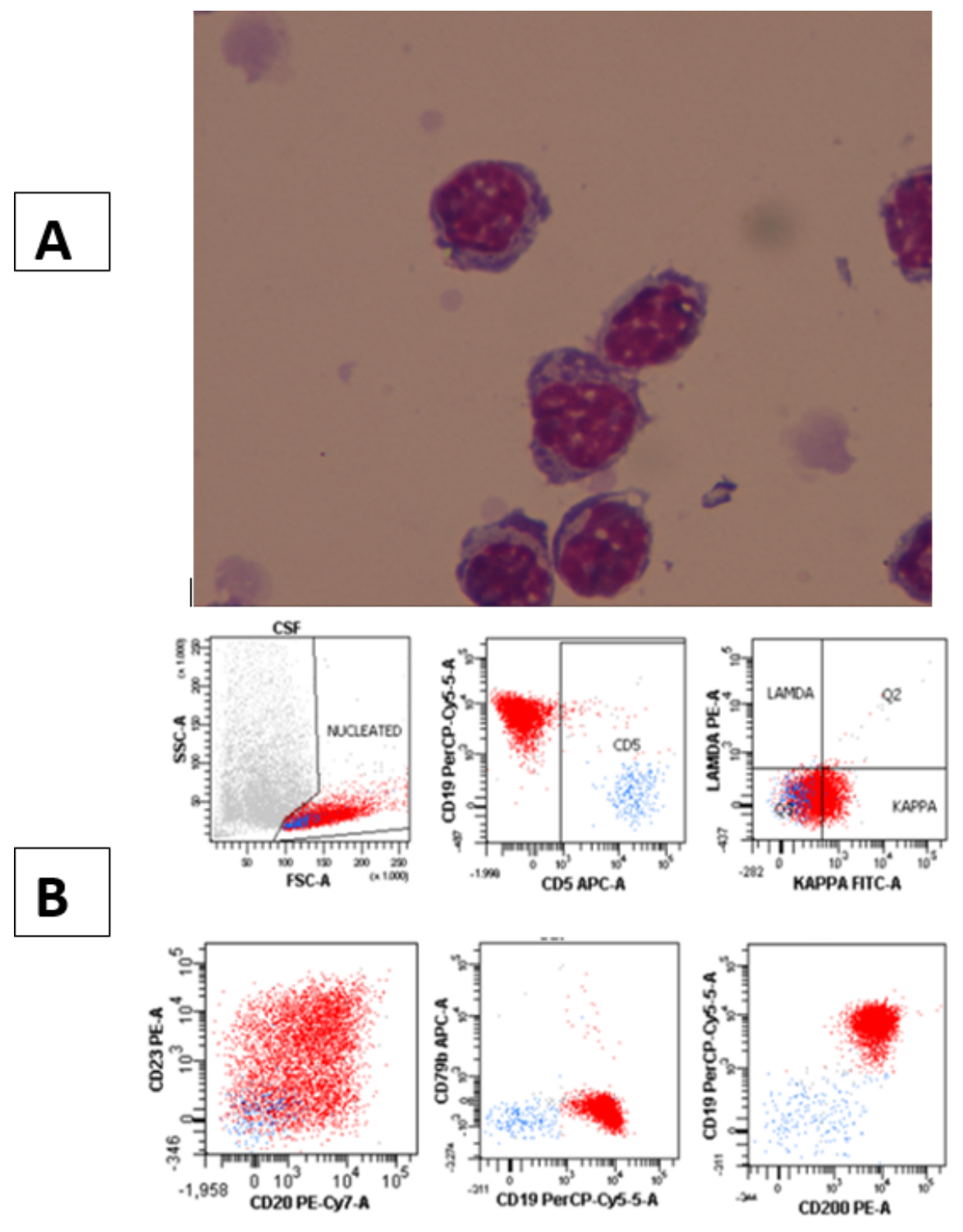

